\section{NEW ZEALAND FOREST SERVICE} REPORT FOR THE YEAR 1950-51

$\mathrm{T}$ THERE is a breezy directness about the annual forestry reports of New Zealand* which should invite public attention. Yet under the heading "Purpose of Annual Report", the Director of Forestry writes: "Practically without exception the annual reports of the Director of Forestry have been used consistently since 1934 to review forest policy. There have been few if any facets of policy that have not been reviewed on numerous occasions. Primarily, these reviews have been intonded to inform Parliament on the Department's discharge of its responsibilities under the various Forest Acts and their amendments. Equally, they have been directed at the public in the expectation that, the annual reports being public documents freely available both to the press and to interested bodies, the public would be adequately informed of the evolution of forest policy. That expectation has proved illusory. A month seldom passes without there being some definite evidence that policy reviews are either not consulted or completely ignored. Clearly, annual reports are insufficient in themselves to promulgate forest policy". In forestry matters the Director is not alone in this discovery.

One of the chief troubles in New Zealand, as elsewhere in both the Old and New Worlds, is fire damage. The Director contrasts New Zealand with Scandinavia where, he says, fire protection work is much less costly because the people have become forest-minded. This is true of the peoples of other parts of Western Europe, and we have yet to acquire this attribute in Great Britain. In New Zealand, on the other hand, says the report, thore is a tradition of land-clearing to make farms, and most of the people of the cities are out of touch with forests and forestry. In order to improve fire publicity, the campaign against fire is now to be merged in public relations affairs.

In the annual report for 1948-49, under forest policy, it was announced that the decision had been taken by the Government to establish a saw mill and a pulp and paper mill at Murupara on the Rangitaiki River in the Rotorua Forest Conservancy -...the first of its type in the Dominion (see Nature, $165,966 ; 1950)$. There was afterwards considerable hesitancy in embarking on this great scheme to exploit the extensive forest in question. The proposed development is of high interest in its novel departure. Later in the year the Government finally took the momentous decision to proceed with the project, and in order that the resources of this great forest may be exploited without further delay, the Government effected, during the 1950 session, the passage of legislation empowering the construction of the Edgecombe-Murupara Railway and granted financial authority for the work.

On the subject of soil conservation, about which so much is talked and written nowadays, the report correctly says : "The joining of soil conservation with river control has served to cloud the fundamental issue that in the final analysis both soil and water problems are essentially land and not engineering problems". The example is given of the failure of the British groundnuts scheme, and allusion is made to serious fears that all is not well with the muchadvertised Tennessee Valley Authority scheme. As

* New Zealand State Forest Service : Annual Report of the Director of Forestry for the Year ending 31st March 1951. Pp. 79. (Wellington: Govt. Printer, 1951.) 18 . $6 d$. is well known, the necessary protection of the headwaters of the various waters upon which the scheme is based was ignored.

It is estimated that 80 per cent of the erosion and flooding troubles of New Zealand would ultimately disappear if land and forest fires could be entirely eliminated; a further 15 per cent would be rectified if overgrazing by wild life and by farm animals could be stopped, and other better farming practices universally instituted.

E. P. Stebiing

\section{METEOROLOGICAL OFFICE}

\section{REPORT FOR THE YEAR $1951-52$}

$\mathrm{T}$

HE principal feature of the report of the Director of the Meteorological Office for the year ending March 31, 1952*, is the attention which is being devoted to the study of the atmosphere in the region between about 30,000 and $50,000 \mathrm{ft}$. in height-roughly the top of the troposphere and the lowest part of the stratosphere. This region is particularly important because jet aircraft fly in it at a fuel consumption which for the distance covered is less than at lower levels. The winds there are sometimes very strong, having been known to exceed 150 knots (about $280 \mathrm{~km}$. $/ \mathrm{hr}$.), and the air is sometimes bumpy for no visible cause (such as thunderclouds) which would give warning to pilots. The forecasting of wind-speed and -direction and turbulence in this region is an important meteorological problem. The increased attention given to the upper atmosphere is partly shown by the formation during the year of a new Branch of the Office for detailed study of the Climatology of the Upper Air ; previously, this work had been the function of a section of the Overseas Climatology Branch. Research into the forecasting of winds at high levels has continued during the year, and analysis of occasions of clear-air turbulence has confirmed earlier indications of an association between turbulence and the presence of marked variation in wind-speed in the vertical and horizontal directions. The work on turbulence included observations by the Meteorological Research Flight of the behaviour of smoke trails emitted by aircraft.

The forecasting of radiation fog is a major meteorological problem of importance to all forms of transport. A special organization was set up at Cardington (Bedford) to examine the development of fog. The work includes observations with the aid of instruments which can be carried by kite-balloon to more than 2,000 ft. Experimental forecasts for four days ahead were prepared twice weekly in the Forecast Research Division. A measure' of success was attained; but the reliability of the forecasts was not sufficient to enable a decision to be made to devote additional staff to this work. Among other subjects of research described in the report are the study of cloud structure by radar, icing on aircraft, and the development of instruments, such as the radar theodolite, for measuring upper winds.

The meteorological services provided for the Royal Air Force and Army, civil aviation, the general public and industry continued to expand. A large meteorological exhibition was set up in the Dome of Discovery of the Festival of Britain Exhibition in

* Annual Report of the Director of the Meteorological Office presented by the Meteorological Committee to the Secretary of State for Air for the Year April 1,1951, to March 31, 1952. (M.O.562.) Pp. 56 . (London: H.M.S.O., 1952.) 28. net. 
London. The exhibition included a weather-forecasting unit at which a special souvenir weather report and forecast was compiled, and more than 150,000 copies were sold to visitors. The overall strength of the Office staff decreased from 2,601 to 2,589 during the year; but the scientific officer class increased from 160 to 165 . A number of university students, mainly of physics and mathematics, worked in the research centres of the Office during vacations.

\section{DRYING OF HIDES AND SKINS}

$I^{\mathrm{T}}$ is twenty years since experimental work in Kenya yielded results which established principles for the correct drying of hides; the experience gained since that time has now been described by J. R. Furlong, principal of the Colonial Products Advisory Bureau (Plant and Animal) (Colonial Plant and Animal Products, 2, No. 4 ; 1951).

To obtain the best possible leather from a hide, it is desirable to proceed to the tanning operations without reducing the hide to a dry state. Many countries, however, have insufficient native hides for their needs, and it is necessary to bring supplies from overseas or long distances to the tanneries. The distance which green or lightly salted hides can safely travel without damage caused by putrefaction is very limited, and it is essential to submit the hides to some process of curing in order that they may be transported and stored without deterioration. The curing may consist of salting the hide and transporting it in a wet-salted condition-an expensive method applicable to the best qualities of hides, or the material, after salting, may be dried out and sent to the market in a dry-salted condition. In many countries, however, salt is scarce and the use of the imported material would be too costly. Recourse is therefore made to the procedure of airdrying as a method of preservation. This is practised in many hot countries, particularly in the African continent. Dry hides represent a large proportion of the production of the entire output of such countries as Nigeria, East Africa, South Africa, the Sudan and Abyssinia, while India and South America are also large producers of dry hides.

Dry hides are an important class of raw material for the tanneries of the world to-day. In the decade before the War many tanners had developed a technique for producing leather of the highest quality from this class of hides, and during the War a still larger number of tanners in the United Kingdom were forced to use Colonial dry hides for the first time. While Continental tanneries had always handled Colonial hides, it is the great advance which has been made in this connexion in the United Kingdom, as a result of war-time experience, that is of significance. Tanners have learnt how to obtain good results, and it is to Colonial sources that English tanneries now look for increasing supplies of their raw materials.

The article describes methods which are now being used in the suspension-drying of cattle, goat and sheep skins, and emphasizes that the old method of drying hides and skins on the ground is liable to cause serious damage, and should never be employed. Drying hides and skins on the ground should be prohibited in areas where the improved processes of suspension-drying are practicable.

\section{HANDLING OF RADIOACTIVE AND TOXIC SUBSTANCES}

$\triangle \mathrm{N}$ edited report of the proceedings of the symA posium on the handling of radioactive and toxic substances, which was organized by the Chemistry Division of the Atomic Energy Research Establishment, Harwell, and which was held in two sessions on September 10-11 and 13-14, 1951, at Buckland House, near Faringdon, Berks, has recently been issued*. Sixty-four representatives from the chemical industry, universities, hospitals, government research establishments and the atomic energy projects of Western European countries attended. A list of the various representatives and their respective organizations is included in the report. The chairman, Dr. R. Hurst, welcomed the representatives, and mentioned that the original suggestion to hold such a symposium came from Dr. R. Spence, the head of the Chemistry Division at Harwell.

The contributed papers and subsequent discussion centred around three topics: the use of glove boxes, remote control of chemical operations and laboratory housekeeping and decontamination. Dr. Hurst, who spoke first, described the various improvements and requirements in the design of glove boxes which experience of their use at Harwell has indicated. $\mathrm{He}$ stated that glove boxes provide the simplest means of confining a chemical operation so as to prevent the spread of radioactivity, or to exclude oxygen, dust or harmful organisms. Suitable gloves developed for use in these boxes were described and shown. The use of heat-sealed polyvinylchloride bags for the transfer of active material or apparatus into or out of glove boxes was recommended. Mr. J. G. Bell then gave details of a glove box design with doublewall protection for work on alpha-active materials which require a protective atmosphere, and $\mathrm{Mr}$. W. G. Busbridge discussed the requirements of filters for use with glove boxes. The disadvantages of woolresin filters were pointed out, and a new type of filter employing a mechanical filter of wool and asbestos was briefly described.

On the subject of remote control of chemical operations, the discussion centred on two general methods : systems of tongs, manipulators and periscopes, by which conventional apparatus can be used by an extension of the hands; and systems by which liquids can be transferred, precipitates removed and similar operations conducted by vacuum-lifting or by pumping from vessel to vessel. In this section papers were read by J. Dean and A. B. Ritchie, G. B. Cook, G. N. Walton, G. Wortley, and Dr. W. J. Arrol. Finally, Dr. G. L. Miles reviewed the general problem of laboratory management in radiochemical work, the housekeeping techniques which are essential to prevent and restrict the spread of radioactivity and to keep the working-space clean and free from contamination. It was emphasized that hoods, glove boxes and apparatus should have hard smooth surfaces, that detergents are generally satisfactory as decontaminants and that certain radioisotopes may need special treatment. Recommendations on the disposal of active waste were also made.

The report makes interesting reading and is amply illustrated by photographs and diagrams.

* Atomic Energy Research Establishment. Symposium on the on September 10-11 and September 13-14, 1951, at Buckland House, neas Faringdon, Berkshire, (A.E.R. C R P58.) Edited by G. R. Hall. Pp. iv $+37+31$ pl. (Iondon: H.M.S.O., 1952.) 128. $6 d$. net 